\title{
IMPROVING THE ACTIVE POWER FILTER PERFORMANCE WITH AN ADAPTIVE LINEAR NEURAL NETWORK BASED ON THE REFERENCE GENERATION
}

\author{
Ahmed M. Dabroom \\ Yanbu Industrial College, Saudi Arabia, Electrical Eng. depart. \\ dbroommohmed@yahoo.com
}

\begin{abstract}
The use of artificial neural networks (ANNs) in power system problems is increasing attention due to their ability to learn and handle the nonlinearities and uncertainties of the systems. Since the last decade, different ANNs identification and filtering techniques have been applied in power systems and adaptive linear neuron networks (ADALINE) are actually widely used. More recently artificial neural networks have been introduced as a complement or an alternative to traditional control algorithms. The use of neural networks in control applications including process control, robotics, industrial manufacturing and aerospace applications, among others has recently experienced rapid growth. This paper proposes a new control method for shunt active power filter, which is based on ANN. An adaptive linear neuron (ADALINE) will be presented to estimate the reference compensation currents. The resultant compensation currents eliminate harmonics and reactive power compensation with a quick dynamic response. Theortical and expermental results in a good agreement.

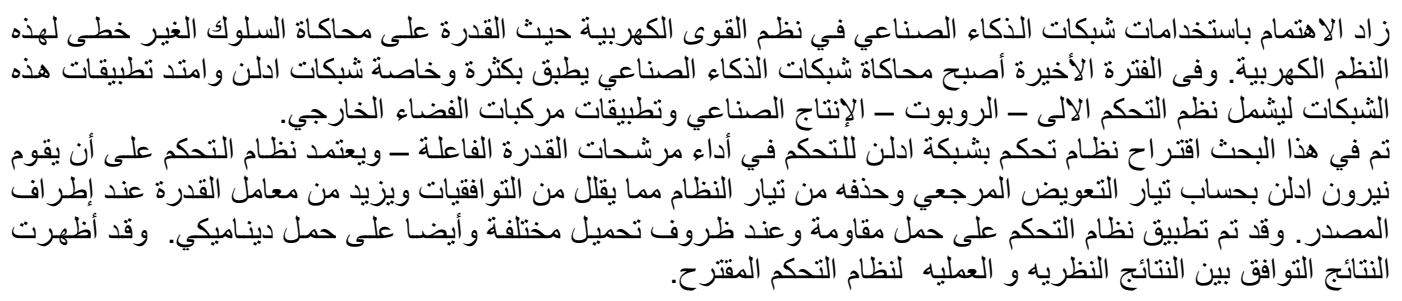

Keywords: Active power filter, Adaptive Linear Neuron (ADALINE), reference current extraction, Digital Signal Processing (DSP).

\section{INTRODUCTION}

There has been a continuous proliferation of nonlinear type of loads in industry as well as by the consumers. Rectifiers, inverters, AC regulator, and other nonlinear loads introduce voltage and currant harmonics in power systems. Currents and voltages are thus nonsinusoidal and it is necessary to compensate the generated harmonics. Active Power Filters (APF) can be employed to compensate harmonics in power systems[1-3]. APF compensation techniques can be easily inserted in existing industrial power systems and are thus widely used. Shunt (APF) compensates current harmonics by injecting equal-but-opposite harmonic compensating current. In this case the shunt active power filter operates as a current source injecting the harmonic components generated by the load but phase shifted by $180 \mathrm{o}$. This principle is applicable to any type of load considered a harmonic source. Moreover, with an appropriate control scheme, the active power filter can also improve power factor at the supply terminals [3-5]. In this way, the power distribution system sees the non linear load and the active power filter as an ideal resistor. The current compensation characteristic of the shunt active power filter is shown in Fig.1.

In this paper an improved scheme is proposed using Adaptive Linear Neuron (ADALINE). The ADALINE neural network uses to separate the 
fundamental component from the distorted supply current. Based on the Fourier series, this new decomposition of current signals allows to define the neural network inputs for which a Least Mean Squares (LMS) algorithm carriers out the weights training. The method utilizes adaptive neurons (ADALINE) to process the signals obtained from the line. This current ADALINE extracts the fundamental components of the distorted line current signal and the output of the ADALINE is compared with distorted supply current to construct the modulating signal. This modulating signal is used to generate the PWM pulses that fed to the active power filter to generate compensating current. This compensating current is fed against to the distorted line current. Thus the power quality will be maintained

[6-7].

\section{ADAPTIVE LINEAR NEURAL NETWORK (ADALINE) PRINCIPLE}

Adalines are simple dynamical learning systems by means of a linear combination of time-dependent signals. Determining the value of its internal weights, referred to as the training, is achieved which effective algorithms such as the LMS learning rule. This particular form of nonlinear regression is fast and accurate. The simplicity of its architecture offers to the Adaline some other advantages: the possibility of interpreting its weights and the possibility of hardware implementation. Fig.2 shows an Adaline which is composed of an input vector (X), a weigh vector $(\mathrm{W})$ and an activation function $\mathrm{f}(\mathrm{W})$. There is a close analogy between artificial neurons and biological neurons. The weight vector $\mathrm{W}=[\mathrm{W} 1$ $\mathrm{W} 2 \ldots \mathrm{Wn}] \mathrm{T}$ corresponds to the set of synaptic strengths of a biological neuron. The input vector $\mathrm{X}$ $=\left[\begin{array}{ll}\mathrm{X} 1 & \mathrm{X} 2 \ldots \mathrm{Xn}\end{array}\right] \mathrm{T}$ of the Adaline corresponds to the set of electrical or chemical signals received by the synapses of the dendrites of a biological neuron. The activation function $y=f(W)$ is the mathematical modeling of the behavior of the core of a biological neuron. Different activation functions are possible in neural networks. The Adaline neuron uses linear activation functions so the output (y) is simply the sum of the weighted inputs $(\mathrm{y}=\mathrm{f}(\mathrm{WTX})=$ $\mathrm{W} 1 \mathrm{X} 1+\mathrm{W} 2 \mathrm{X} 2+\ldots \ldots \ldots+\mathrm{WnXn})$.

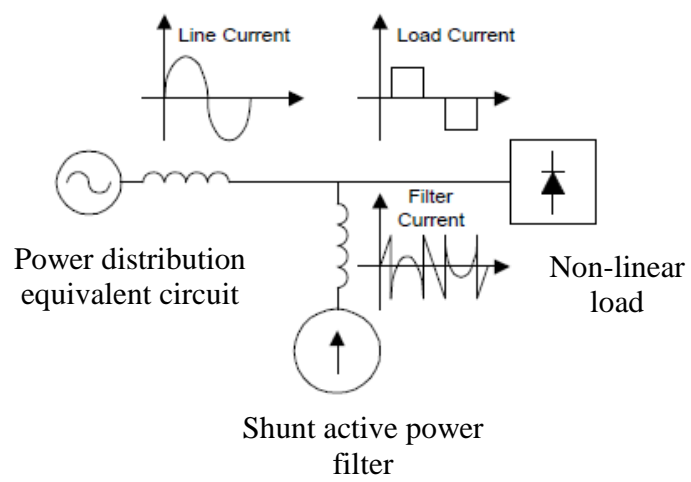

Fig.1 Compensation characteristics of a shunt Active Power Filter

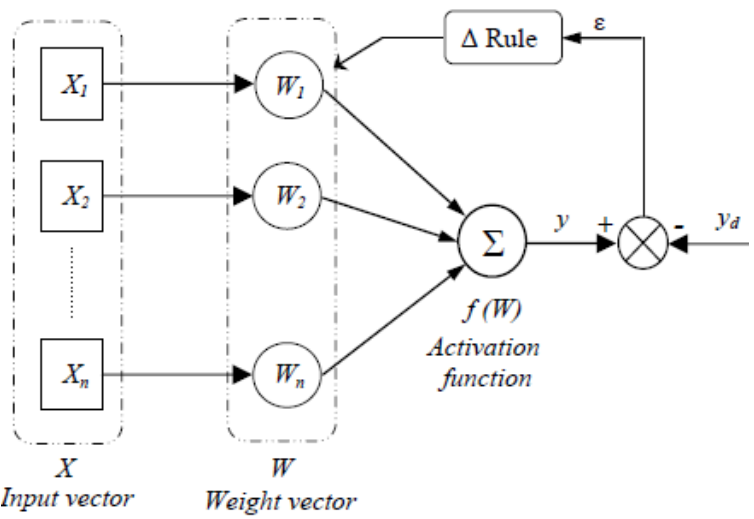

Fig.2 Adaptive Linear Neural Network (ADALINE) principle

When a neuron is excited it produces an output (y) which depends on its inputs. In an Artificial Adaline Neuron these modifications correspond to weight changes. The (W) vector is constantly modified during the life of the neuron or during the training or learning process. In the theory of artificial neural networks the learning process may be divided in two major categories: on-line and off-line training. The Adaline is an on-line trained neuron, this means that the training process of the Adaline is carried all time. Other kinds of neural networks are trained only once so that the network is effectively used only after a fixed set of synaptic weights is obtained (generally after a very long training process). A learning rule must be found to correctly update (or modify) the weight vector $\mathrm{W}$ of an artificial neuron. Since neurons are generally part of a more complex system which is capable to learn or acquire knowledge (the human brain, for instant) the process of synaptic weight updating is called a learning process. One says that a neuron is undergoing a learning process when $\mathrm{W}$ is being updated. Adalines are trained by an on-line learning process based on a least mean square 
(LMS) algorithm which called delta ( $\Delta$-rule). The $\Delta$ rule is based on the LMS minimization of a quadrature error. It can be considered a classical problem of minimizing a cost function. This is a very interesting subject that is not in the scope of this paper. The authors recommend the careful reading for a better understanding of the Adaline network and its $\Delta$-rule. For the purposes of this research it is enough to know that the $\Delta$-rule is given by equation (1).

$$
\mathrm{W}(\mathrm{k}+1)=\mathrm{W}(\mathrm{k})+\alpha \varepsilon \frac{\mathrm{X}(\mathrm{k})}{\mathrm{X}^{\mathrm{T}}(\mathrm{k}) \mathrm{X}(\mathrm{k})}
$$

In equation (1):

- The index $\mathrm{k}$ corresponds to the discrete instant kT

- $(\alpha)$ is the learning rate of the neuron,

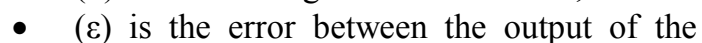
neuron and the desired output $\varepsilon=\mathrm{y}-\mathrm{y}_{\mathrm{d}}$

- $\mathrm{X}(\mathrm{k})$ is the input vector and $\mathrm{X}^{\mathrm{T}}(\mathrm{k}) \mathrm{X}(\mathrm{k})$ is the norm of the input vector.

The learning rate $(\alpha)$ is an important parameter. A high $(\alpha)$ increases the learning speed but cannot warranty an accurate learning (i.e. the minimum error between the output and the desired output may be too high). A small $(\alpha)$ decreases the learning speed but can provide a small error.

\section{ADALINE BASED FOURIER SERIES}

In the pervious section it was seen that the weights of the Adaline are updated by the $\Delta$-rule so that the error $(\varepsilon)$ is minimum. This means that the output ( $\mathrm{y}$ ) of the Adaline is forced to follow a desired output ( yd).If ( yd ) is a time-varying signal the adapting or learning process must be carried in real time and must be fast enough in order to produce a small error at every time instant. As discussed previously, a reasonably high (but small enough to provide a small error) value of $(\alpha)$ allows a fast convergence, thus the Adaline weight vector $\mathrm{W}$ can be adapted in real time so that $\mathrm{y}=\mathrm{yd}$ even if yd changes with time and is not periodic. After a brief adapting process the weight vector $\mathrm{W}$ becomes quasi stationary (because $\varepsilon$ becomes low and the weight increases or decreases become small) if (yd) is periodic, i.e. the Adaline learns how to generate the output $\mathrm{y}$ (so that $\mathrm{y} \approx \mathrm{yd}$ ). Whenever the waveform of (yd) is altered another adapting process is started so that a new vector $\mathrm{W}$ is determined (with a low $\varepsilon$ at the end of the process), i.e. the Adaline need to learn again. The adaptive behavior of the Adaline can be used to find the Fourier Series approximation of the signal (yd). This can be achieved if the inputs of the Adaline are sine and cosine functions of fundamental and harmonic frequencies. Fig. 3 shows how this is done. A periodic waveform can be expanded by
Fourier analysis of the time function (yd) is given by eqation. (2). The series contains (N) oscillatory components and one constant component. The trigonometric functions have angular frequencies $n \omega$, where $\mathrm{n}$ is the harmonic order ( $\mathrm{n}=1$ corresponds to the fundamental frequency).

$y_{d}(t)=A_{0}+\sum_{n=1}^{N} C_{n} \sin \left(n \omega t+\varphi_{n}\right)$

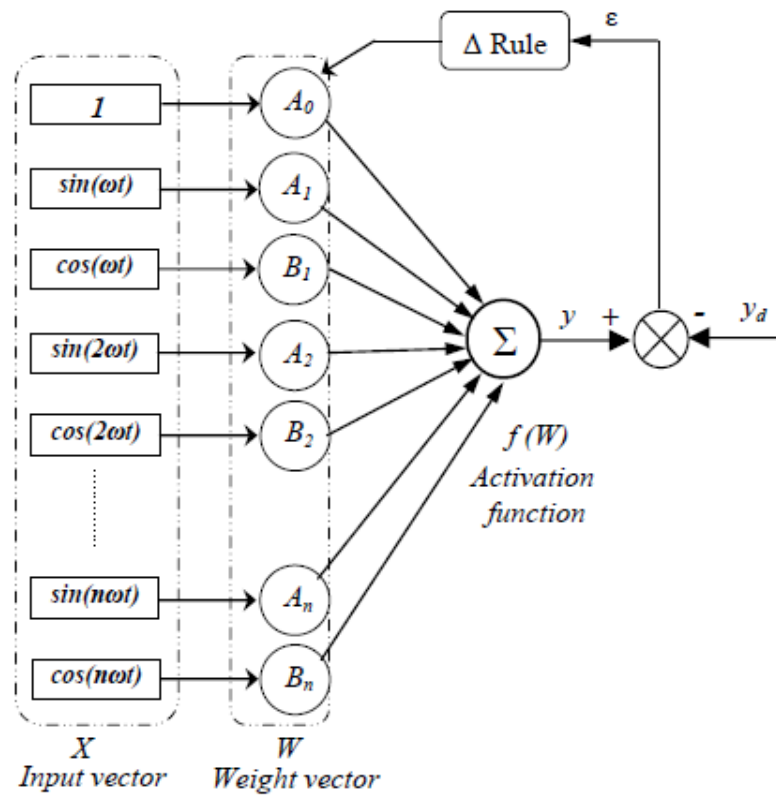

Fig.3 Fourier series with (ADALINE)

Equation (2) may be rewritten as (3), where each oscillatory component is expressed as a sum of two trigonometric functions.

$y_{d}(t)=A_{0}+\sum_{n=1}^{N} A_{n} \sin (n \omega t)+\sum_{n=1}^{N} B_{n} \cos (n \omega t)$

The relation between the amplitudes of the oscillatory terms of Equations (2) and (3) is given by equation (4) and the displacement angle $\varphi n$ is given by equation (5). Equation (5) is not used in the compensation method proposed in this paper because the Fourier series in the form of equation (3) is used. Equation .(4) is used because the compensation method needs to determine the amplitudes of the fundamental electric currents, as will be explained later.

$$
C_{\mathrm{n}}=\sqrt{\mathrm{A}_{\mathrm{n}}^{2}+\mathrm{B}_{\mathrm{n}}^{2}}
$$


$\varphi_{\mathrm{n}}=\tan ^{-1} \frac{\mathrm{B}_{\mathrm{n}}}{\mathrm{A}_{\mathrm{n}}}$

Equation (6) is the discrete form of equation (3), because the compensation method is intended to be implemented in digital processors.It is convenient to write equation (6), where the index $\mathrm{k}$ corresponds to the $\mathrm{k}$-th discrete time instant. The sampling interval $\mathrm{T}$ is the same used in the $\Delta$-rule of Equation (1). When the Adaline of Fig.3 is used to determine the Fourier series of $y d$ the weight vector $\mathrm{W}$ undergoes an adaptive updating process with the $\Delta$-rule of equation (1). If the error $\varepsilon$ is sufficiently small the components of the weight vector are the coefficients of the Fourier series of the time function yd.

$y_{d}(t)=A_{0}+\sum_{m=1}^{N} A_{n} \sin (n \omega k T)+\sum_{n=1}^{N} B_{n} \cos (n \omega k T)$

For simplicity, the input vector $\mathrm{X}$ (in the discrete form) and the weight vector $\mathrm{W}$ of the Adaline of Fig.(2) are written in equations (7) and (8).

$\mathrm{X}=[1 \sin (\omega \mathrm{kT}) \cos (\omega \mathrm{kT}) \sin (2 \omega \mathrm{kT}) \cos (2 \omega \mathrm{kT})$ $\ldots=\sin (\mathrm{N} \omega \mathrm{kT}) \cos (\mathrm{N} \omega \mathrm{kT})]^{\mathrm{T}}$

$W=\left[\begin{array}{lllllll}A_{0} & A_{1} & B_{1} & A_{2} & B_{2} & \ldots . & A_{N} \\ B_{N}\end{array}\right]^{T}$

\section{DETERMINATION OF COMPENSATING CURRENTS}

REFERENCE

A- General description of the system

The basic principle of the proposed control system to get the reference compensating currents of shunt APF is shown in Fig.4, where the figure shows the basic elements of control system. This scheme is mainly composed of an adaptive linear neural network (Adaline), phase locked loop circuit (PLL) and hysteresis current controller. The adaptive ANN extraction circuit, hysteresis control and the PLL circuit are integrated as an overall mode of adaptive shunt APF. In this circuit, the Adaline network will take information from the nonlinear load currents to estimate the reference compensation currents by identifying the harmonics with a Fourier expansion of the load currents and direct component of supply voltages. The PLL circuit generates sinusoidal signals with constant unit amplitude, even if the supply voltage has a distortion. Finally, the reference compensating currents of shunt APF are compared with its actual and the error fed to hysteresis current controller to obtain the switching of voltage source inverter (VSI) for injecting phase-opposite the harmonic currents in the power system. The following subsection outline the detailed control schemes of the proposed system.

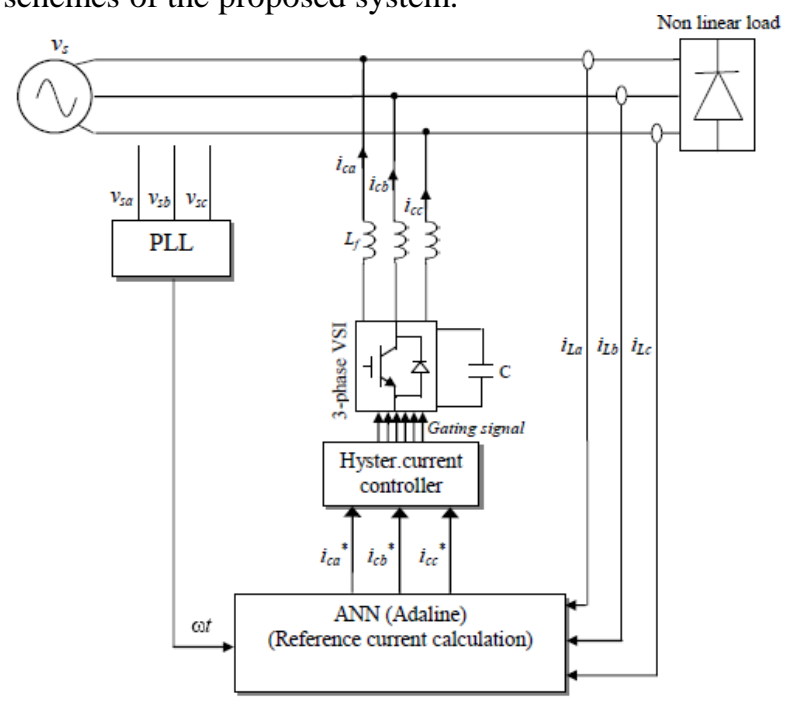

Fig.4 Basic elements of control system.

\section{B-Learning with Adalines}

The harmonic and reactive compensation of the proposed system using Adaline-based approach is outlined as follows:

Considering phase (a) as studying case using Fourier series, the nonlinear load current waveform can be represented by equation (9):

$\mathrm{I}_{\mathrm{L}}(\mathrm{t})=\sum_{\mathrm{n}=1}^{\mathrm{N}} \mathrm{I}_{\mathrm{n}} \sin \left(\mathrm{n} \omega \mathrm{t}+\phi_{\mathrm{n}}\right)$

Where:

n: harmonic order;

$\mathrm{N} \quad$ order of highest harmonic;

$\mathrm{I}_{\mathrm{n}} \quad$ magnitude of nth harmonic;

$\emptyset_{n} \quad$ phase angle of nth harmonic

In harmonic extraction procedure, the equation (9) can be expanded as follows:

$$
\begin{aligned}
& \mathrm{i}_{\mathrm{L}}(\mathrm{t})=\sum_{\mathrm{n}=1}^{\mathrm{N}} \mathrm{I}_{\mathrm{n}} \sin (\mathrm{n} \omega t) \cos \left(\emptyset_{\mathrm{n}}\right)+\mathrm{I}_{\mathrm{n}} \cos (\mathrm{n} \omega t) \sin \left(\emptyset_{\mathrm{n}}\right) \\
& =I_{1} \sin (\omega t) \cos \left(\phi_{1}\right)+I_{1} \cos (\omega t) \sin \left(\phi_{1}\right) \\
& +\sum_{n=2}^{\mathbb{N}} I_{n} \sin (n \omega t) \cos \left(\phi_{n}\right)+I_{n} \cos (n \omega t) \sin \left(\phi_{n}\right)
\end{aligned}
$$

Where:

The first term without summation corresponds to fundamental frequency; 
$I_{1}$ and $\emptyset_{1}$ are the magnitude and phase angle, respectively.

- The second term with summation corresponds to $\mathrm{n}^{\text {th }}$ harmonic from $\mathrm{n}=2$ to $\mathrm{n}=$ $\mathrm{N}$, and similarly, $\mathrm{I}_{\mathrm{n}}$ and $\emptyset_{\mathrm{n}}$ are the magnitude and phase angle, respectively.

Equation (11) can be written as:

$i_{L}(t)=W_{1} \sin (\omega t)+W_{2} \cos (\omega t)+W_{3} \sin (2 \omega t)+W_{4} \cos (2 \omega t)+\cdots+W_{2}$ $+W_{2 n} \cos (n \omega t)$

Where:

$W_{1}=I_{1} \cos \left(Q_{1}\right)$ and $W_{2}=I_{1} \sin \left(Q_{1}\right)$

Equation (13) is the discrete form of equation (12)

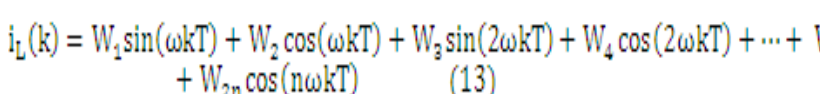

The proposed control method is based on three Adaline neurons (Adaline neuron for each phase), but for simplicity, the studying will be investigated in one phase. To construct the adaptive ANN (Adaline) for one phase, the equation (13) is used and according to equations (7) and (8) from the pervious section, the input vector $\mathrm{X}$ to the adaptive ANN is first determined as:

$[\mathrm{X}]^{\mathrm{T}}=[\sin (\omega \mathrm{kT})$

$\ldots \sin (n \omega K T) \cos (n \omega K T)]$

and the weight vector $\mathrm{W}$ of the Adaline is:

$\left[\mathrm{W}^{\mathrm{T}}=\left[\begin{array}{lllll}\mathrm{W}_{1} & \mathrm{~W}_{2} & \mathrm{~W}_{3} & \ldots \mathrm{W}_{2 n-1} & \mathrm{~W}_{2 n}\end{array}\right]\right.$

Fig.5 describes the Adaline structure with the input vector $(\mathrm{X})$ being the $\mathrm{AC}$ components and the weights (W) correspond to the amplitudes of each harmonic current multiplied with alternatively $\cos \varphi$ or $\sin \varphi$. As shown in Fig.5, the output of the neuron is sum of the product $\mathrm{W}^{\mathrm{T}} \mathrm{X}$, which itself is estimated current $\left(i_{\text {La }}\right.$ est $)$ of nonlinear load. The error $\varepsilon_{a}$ is the difference between the output of the neuron $\left(\mathrm{i}_{\text {La est }}\right)$ and the measured nonlinear load current $\left(\mathrm{i}_{\mathrm{La}}\right)$. This error signal is then propagated backward through the network, against the direction of synaptic connection. The synaptic weights are adjusted so as to make the actual response of the network move close to the desired response. The learning process performed with the error back- propagation algorithm is called back- propagation learning. Back propagation was created by "Widrow" (the Least Mean Square LMS). The Least Mean Square (LMS) algorithm can be considered a special case of the $\Delta$-learning rule, it is independent of the activation function of neurons. Based on the LMS learning rule this model represents the simplest intelligent self-learning system that can adapt itself to achieve a given linear modeling task. The problem consists in finding a suitable set of weights such that the input-ouput behavior of the Adaline becomes close to a set of desired input-output data points linked with a linear relationship. The Adaline weights are solved using an iterative linear LMS algorithm in order to minimize the estimation error. The LMS algorithm is designed with a single linear neuron model see (Fig.5); in this "ciase the design of the LMS algorithm is very simple. The Adaline weights are adjusted according to:

$\mathrm{W}_{\mathrm{k}+1}=\mathrm{W}_{\mathrm{k}}+\alpha \varepsilon_{\mathrm{a}} \mathrm{X}(\mathrm{k})$

Where $\alpha$ is learning rate or called convergence coefficient chosen between 0 and 1 . As shown by

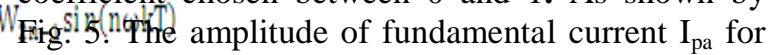
phase (a) is extracted from the Adaline's weights using the first and second elements of the vector $\mathrm{W}$ of the Adaline as follows:

$$
I_{p a}=\sqrt{W_{1}^{2}+W_{2}^{2}}
$$

A similar situation takes place in other Adalines for phases $a, b$ and hence three values of the amplitudes of fundamental currents $I_{p a}, I_{p b}$ and $I_{p c}$ can be obtained. These three values are averaged to balance T) the system written as;

$$
I_{\mathrm{pawg}}=\left(\mathrm{I}_{\mathrm{pa}}+\mathrm{I}_{\mathrm{pb}}+\mathrm{I}_{\mathrm{pc}}\right) / 3
$$




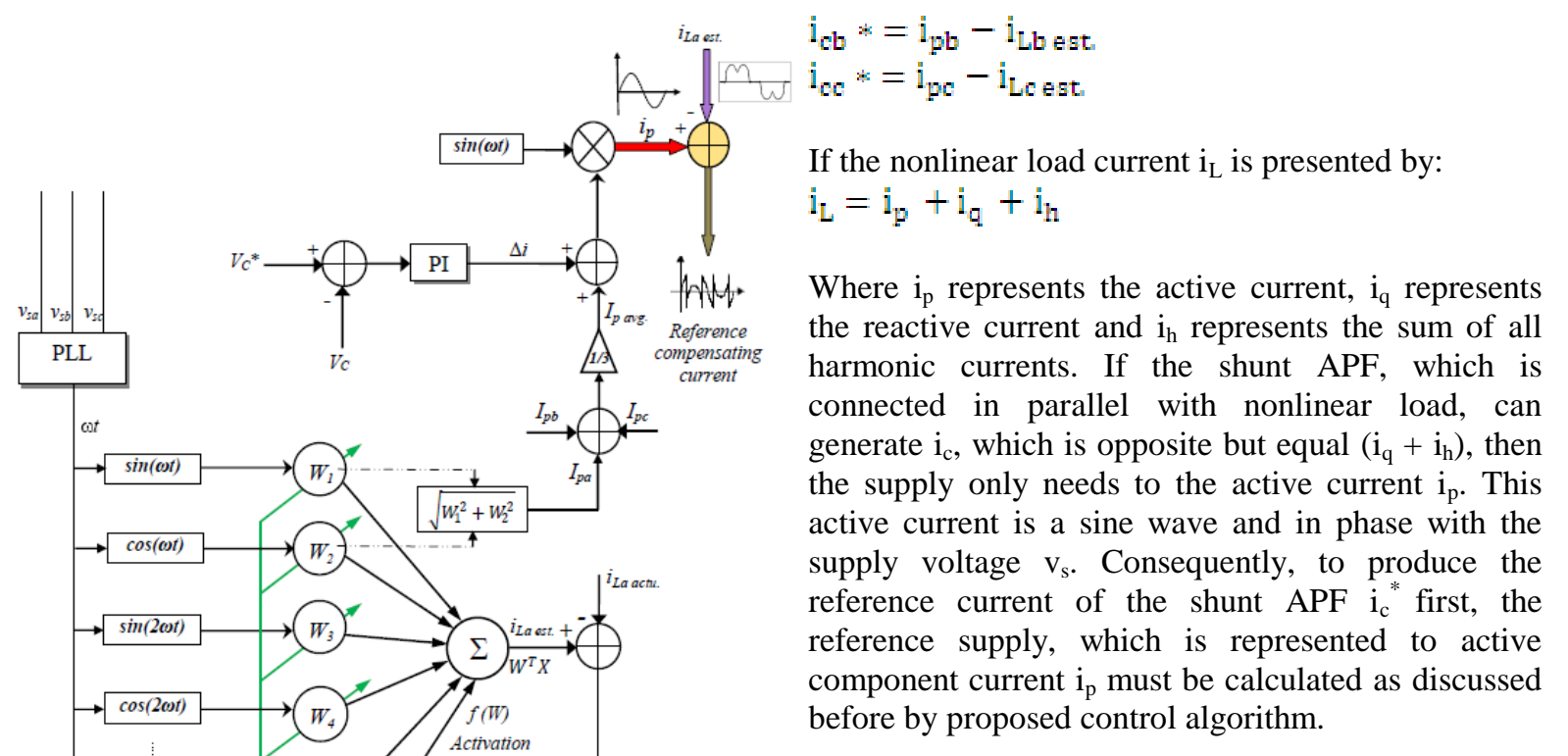

\section{SIMULATION RESULTS OF PROPOSED ADALINE}

The simulation of the proposed Adaline is carried on MATLAB/ Simulink as represented in the Fig.5. Simulation results have been achieved with Adaline algorithm, under different conditions of main voltage and another more disturbance when using nonlinear load such as: three phase controlled rectifier at specific firing angle of thyristor. Also the compensating of shunt APF with multiple loads is examined and discussed.

A number of simulation results with different operating conditions were developed. In Fig.6, shunt APF is connected in parallel with different nonlinear loads, the three-phase controlled rectifier by switch $\mathrm{SW}_{1}$ and induction motor by switch $\mathrm{SW}_{2}$.

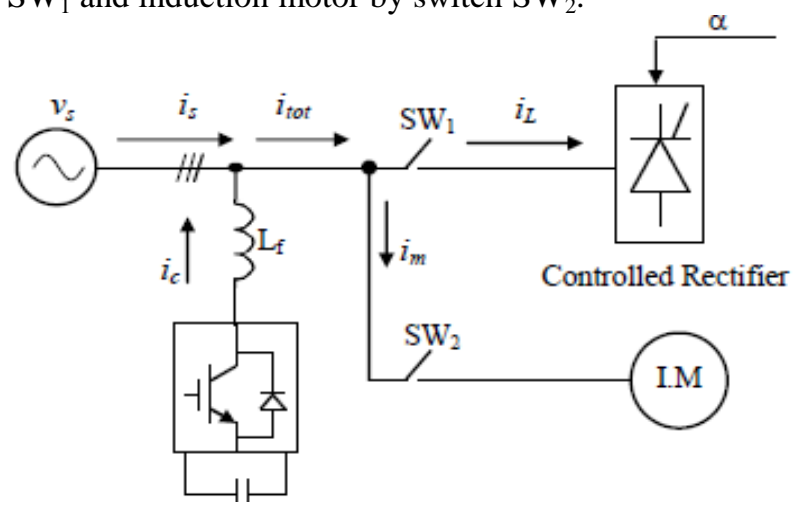

Fig.6 Shunt APF connected in parallel with multiple loads

Finally, the estimation load currents, which are output of Adaline neurons $\left(\mathrm{i}_{\text {Lest. }}\right.$.) are subtracted from the active component currents $i_{p}$ (in- phase with supply voltages), the reference currents of the shunt APF can be obtained the following equation.

$\mathrm{i}_{\mathrm{ca}} *=\mathrm{i}_{\mathrm{pa}}-\mathrm{i}_{\text {La est: }}$

\subsection{Three-phase controlled rectifier:}

When switch sw1 in Fig.6 is only closed, and then the three-phase controlled rectifier with resistive load has to be compensated by the APF. Unfortunately, this controlled rectifier has the inherent problem that the power factor decreases as the firing angle 
increases and that harmonics of the supply current are high. Since the compensation of the shunt APF depends on the firing angle $(\alpha)$ of the rectifier, two different values for the firing angle $\alpha=0^{\circ}$ and $\alpha=40^{\circ}$ have been considered.

\subsubsection{Ideal mains voltage case and firing angle $\alpha=0^{\circ}$}

The waveforms obtained with Adaline algorithm in this case are presented in Fig.7.The supply current $i_{\text {sa }}$ and its spectrum before compensation are shown in Fig.7-a,b. On the other side the supply current $i_{\text {sa }}$ and its spectrum after compensation are shown in Fig.7c,d. Fig.7-e shows the fundamental active component current for phase (a) $i_{\mathrm{pa}}$. While Fig.7-f shows the averaged of amplitudes of fundamental currents ( $I_{\text {pavg. }}$ ). The shunt APF current $i_{c}$ composed to its reference current $i_{c}{ }^{*}$ and the error between them are presented in Fig.7-g,h . The capacitor voltage and its reference are shown in Fig.7-j. As can be remarked, the results have shown that, the supply current after compensation is almost sinusoidal and in phase with corresponding voltage. Also, good tracking of the shunt APF actual current for its reference. Total harmonic distortion (THD) has been calculated of the supply current before and after compensation. The figures and calculation show that THD improved from $22.8893 \%$ (before compensation) to $0.08 \%$ (after compensation).

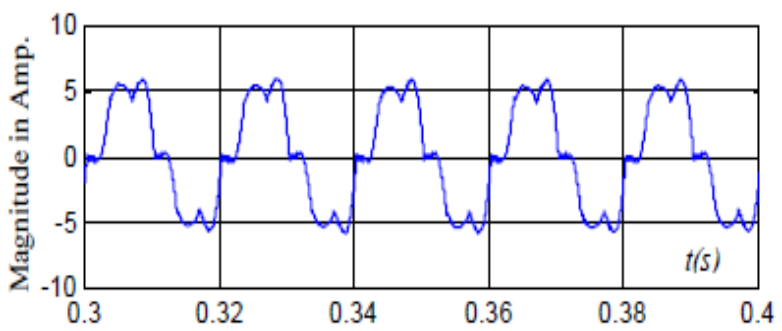

Fig.7-a The supply current before compensation

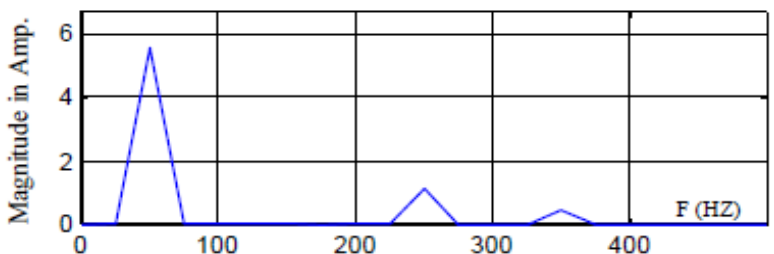

Fig.7-b The supply current spectrum before compensation

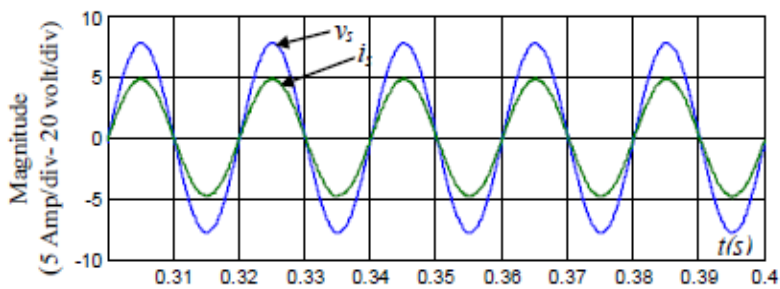

Fig.7-c The supply current after compensation with its respective voltage

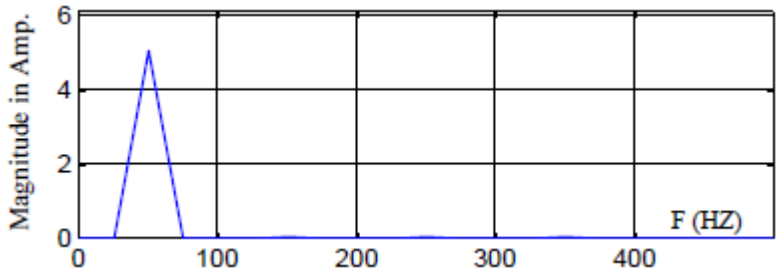

Fig.7-d The supply current spectrum after compensation

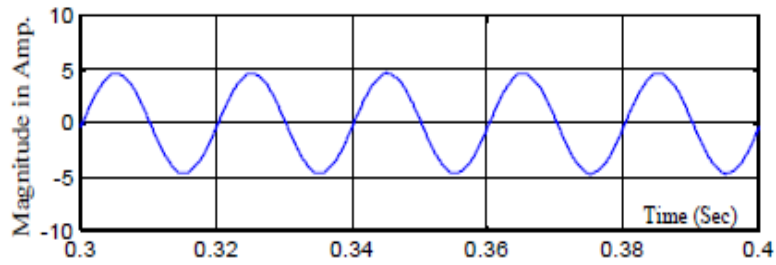

Fig.7-e The fundamental active component current $i_{p a}$

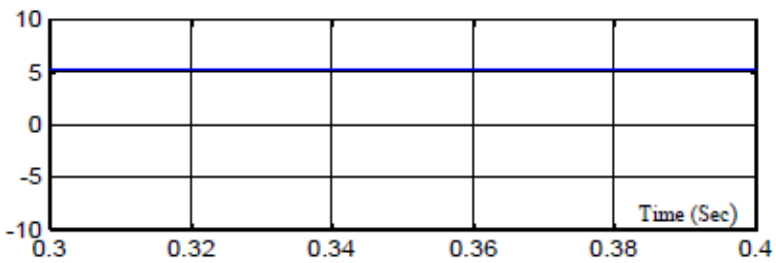

Fig.7-f The averaged of amplitudes of fundamental currents $\left(I_{\text {pavg. }}\right.$.

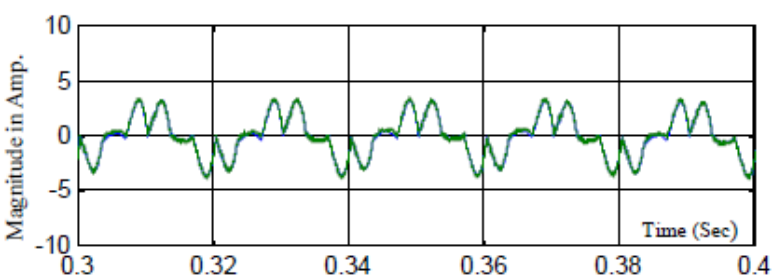

Fig.7-g The APF current $i_{c}$ with its reference $i_{c}{ }^{*}$

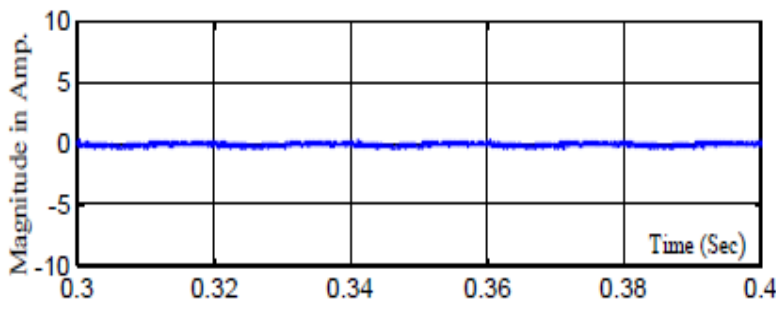

Fig.7-h The current error E between $i_{c}$ and $i_{c}{ }^{*}$

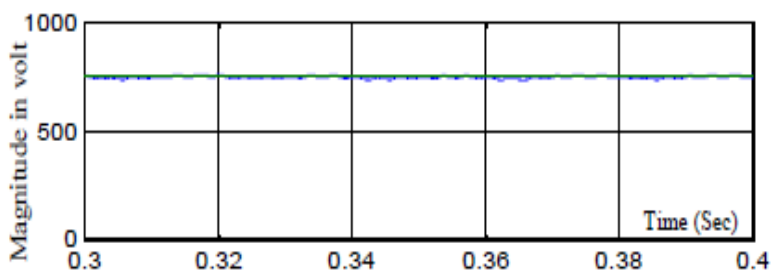

Fig.7-j The capacitor voltage Vc of the APF composed to its reference 
5.1.2 Simulation results at firing angle $\alpha=40^{\circ}$ :

Another case with more distortion in the nonlinear load current is discussedat $\alpha=40^{\circ}$. Fig. 8 , shows the simulation results when the firing angle of controlled rectifier $\alpha=40^{\circ}$, to change of nonlinearity of the load. Fig.8-a shows the supply current $i_{\text {sa }}$ without APF. The supply current $i_{\text {sa }}$ with APF and the supply voltage $\mathrm{v}_{\mathrm{sa}}$ are shown in Fig.8-b. Figure 8-c shows the fundamental active component current $i_{\mathrm{pa}}$, which is in phase with supply voltage. Also Fig.8-d shows the averaged of amplitudes of fundamental currents ( $I_{\text {pavg. }}$.) The APF current $i_{c}$ compared with its reference current $\mathrm{i}_{\mathrm{c}}{ }^{*}$ and the current error $\mathrm{E}$ between them are shown in Fig. 8-e and Fig. 8-f respectively. The capacitor voltage $V_{C}$ compared with its reference $\mathrm{V}_{\mathrm{C}}{ }^{*}$ are shown in Fig.8-g. Figures 8-h,j show the source current $i_{\text {sa }}$ spectrum referred to the amplitude of the fundamental current before and after applied APF. Total harmonic distortion (THD) has been calculated for the current before and after compensation. The calculation shows that THD has been improved from $25.7017 \%$ without the APF to $1.5177 \%$ with the APF.
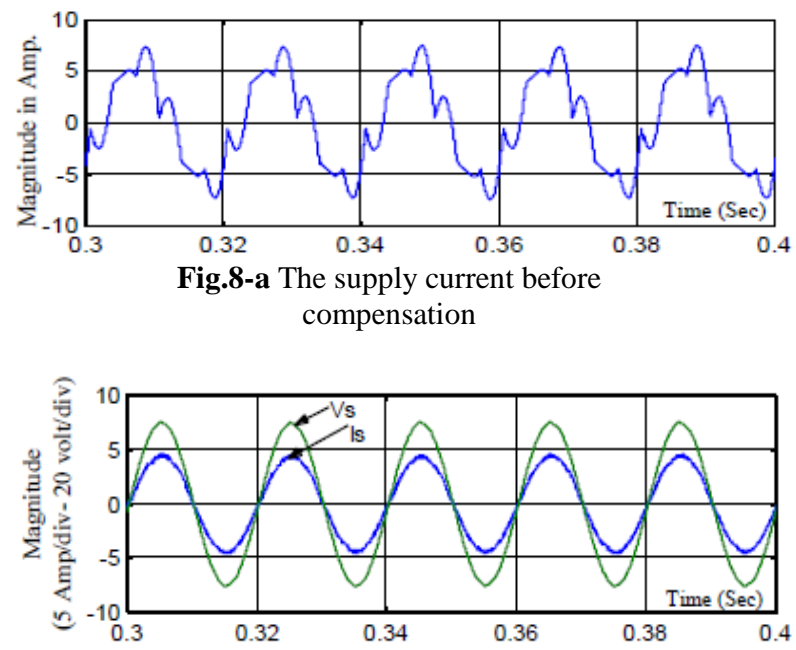

Fig.8-b The supply current after compensation

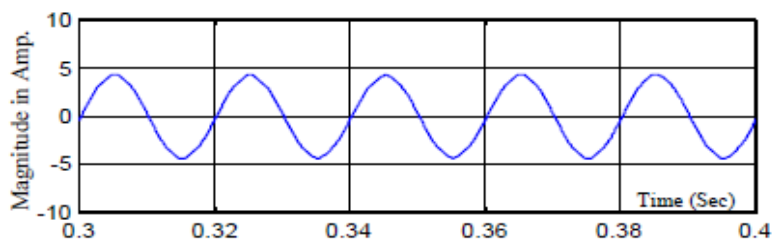

Fig.8-c The fundamental active component current $i_{p a}$

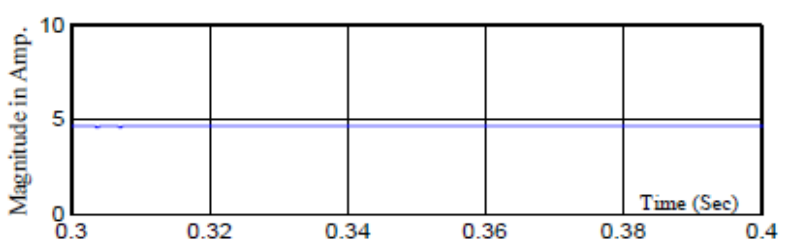

Fig.8-d The averaged of amplitudes of fundamental currents $\left(I_{\text {pavg }}.\right)$

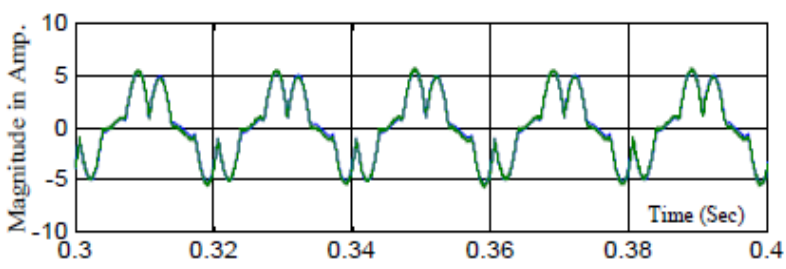

Fig.8-e The APF current $i_{c}$ with its reference $i_{c}{ }^{*}$

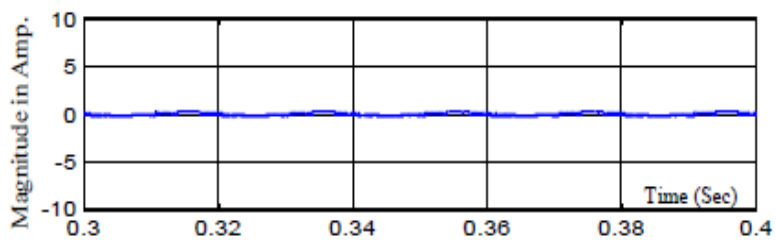

Fig.8-f The current error E between $i_{c}$ and $i_{c}{ }^{*}$

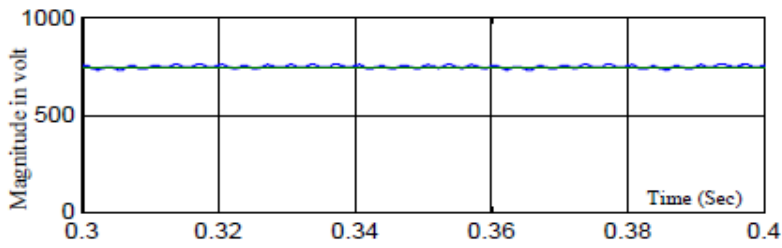

Fig.8-g The capacitor voltage Vc of the APF composed to its reference
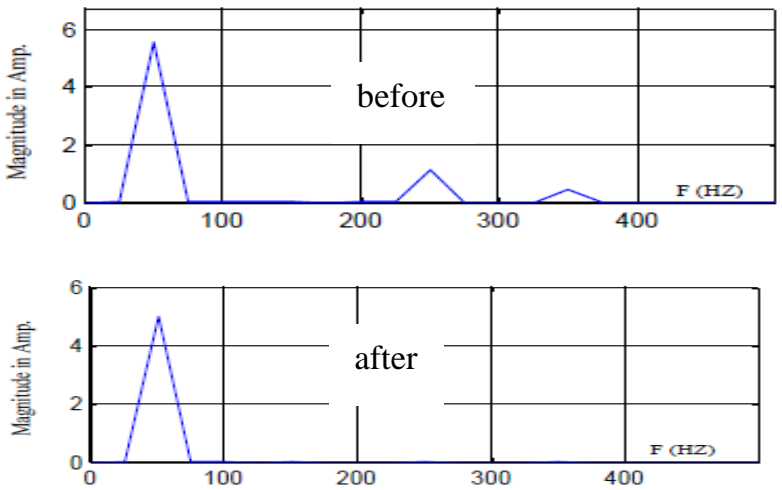

Fig.8-h,j The supply current spectrum before and after compensation

Through the waveforms in Fig.8 it is noticed that, the proposed Adaline design suitable for different cases of nonlinearity load, where the supply current $i_{\text {s }}$ with APF is sinusoidal and still in phase with the supply voltage $v_{s}$. The APF current $i_{c}$ follows its reference $i_{c}{ }^{*}$. It can be seen, for this control technique, the quality of the harmonic and reactive power compensation is not significantly affected by the change in the firing angle.

\subsection{Multiple loads}

In industrial application shunt APF may be connected in parallel with different nonlinear loads as shown in 
Fig. 6, the three-phase controlled rectifier by switch $\mathrm{SW}_{1}$ and induction motor by switch $\mathrm{SW}_{2}$.the induction motor regularally has a low lagging powerfactor at run-up and steady state operation. To compensate these undesirable effects, shunt APF is generally used as a reactive power source during both run-up and running, and consequently the power factor will be improved. From Fig.6 when the switch $\mathrm{SW}_{1}$ is still on and switch $\mathrm{SW}_{2}$ closed, then the threephase controlled rectifier with resistive load (in case of $\alpha=0^{\circ}$ ) and induction motor act as a multiple load, which have to be compensated by the shunt APF. Fig.9 shows the simulation results of a multiple load, where the Fig. 9-a shows the induction motor current $\left(i_{\text {ma }}\right)$ with its respective supply voltage $v_{\mathrm{sa}}$, while Fig.9-b shows the supply current $i_{\mathrm{sa}}=\mathrm{i}_{\mathrm{La}}+\mathrm{i}_{\mathrm{ma}}$ before compensation. The supply current $i_{\mathrm{sa}}$ with supply voltage $v_{\mathrm{sa}}$ after compensation is shown in Fig.9-c. As can be seen from the figures, the induction motor current $\left(i_{m a}\right)$ has a lagging power-factor during the running period and the supply current $\left(\mathrm{i}_{\mathrm{sa}}=\mathrm{i}_{\mathrm{La}}+\mathrm{i}_{\mathrm{ma}}\right)$ of the multiple load before compensation is nonsinusoidal and include distortion. The supply current $\mathrm{i}_{\mathrm{sa}}$ after compensation became sinusoidal and in phase with its respective voltage $\mathrm{v}_{\mathrm{sa}}$. It is proved that, the shunt APF reduces the reactive power drawn from the source and improves the power-factor. Fig.9-d,e shows current spectrum of the supply current $i_{\text {sa }}$ referred to the amplitude of the fundamental before and after compensation, where the Fig.9-d shows the source current $i_{\mathrm{sa}}$ spectrum before compensation and Fig.9-e depicts the source current $i_{\text {sa }}$ spectrum after compensation. In order to evaluate the good performance of the control, total harmonic distortion (THD) is take account before and after compensation. The calculation shows that THD has been improved from $20.1515 \%$ without the shunt APF to $1.01 \%$ with the shunt APF.

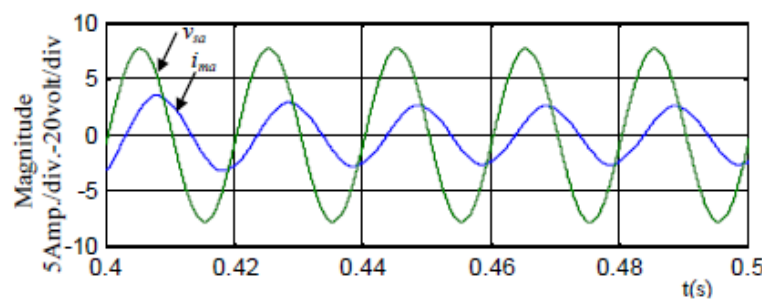

Fig.9-a The induction motor current $i_{m a}$ and the supply voltage $v_{s a}$

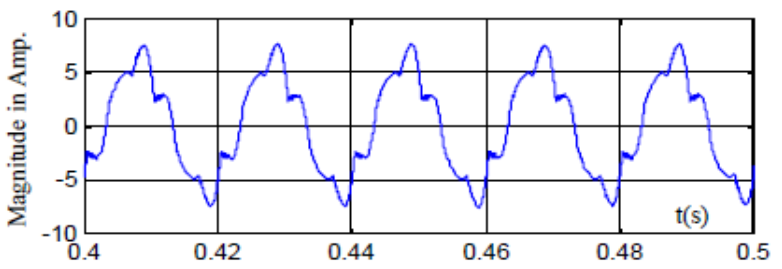

Fig.9-b The supply current $\left(i_{s a}=i_{L a}+i_{m a}\right)$ before compensation
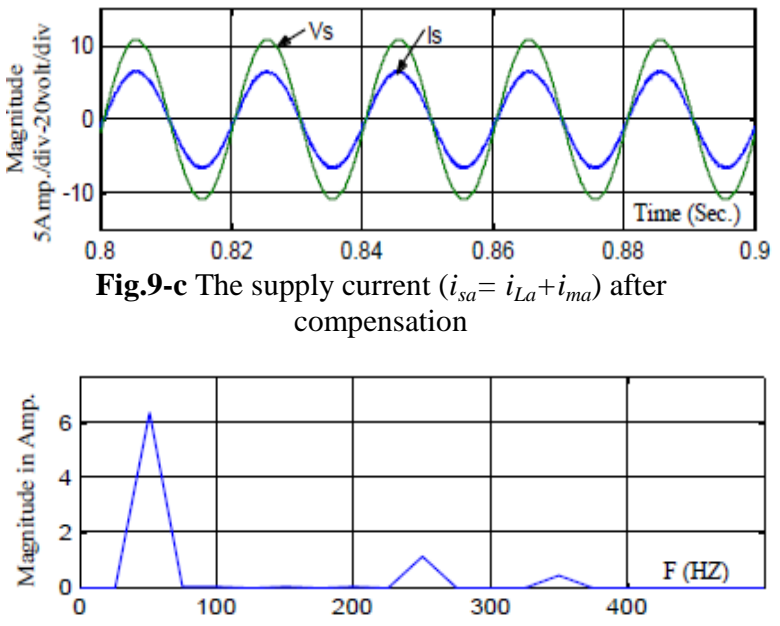

Fig.9-d The supply current spectrum $\left(i_{s a}=i_{L a}+i_{m a}\right)$ before compensation

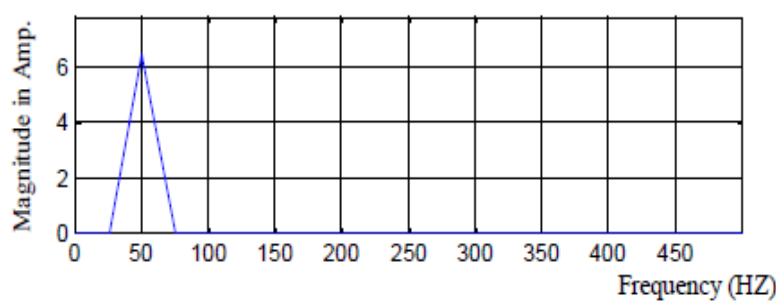

Fig.9-e The supply current spectrum $\left(i_{s a}=i_{L a}+i_{m a}\right)$ after compensation

\subsection{Induction motor direct on line start up}

A direct on line start up of an induction motor can cause a significant voltage dip, and the power factor during a direct on line start is small while the start up apparent power is often very high in comparison with the rated power. Traditionally compensation the reactive power is performed by switched capacitor banks, which are connected in shunt with the load. This technique however is slow, inaccurate and involves bulky and expensive capacitors. Since the shunt APF is more flexible and has higher speed of response, the simulation results of the starting current of the induction motor, with and without compensation are compared to investigate the effectiveness of the compensation performed by the shunt APF. Fig.10 shows the waveforms during the start up of induction motor. Fig. 10-a and Fig.10-b shows the supply current $i_{s}$ with its respective supply voltage $\mathrm{v}_{\mathrm{s}}$ of an induction motor without and with compensation respectively. Whereas Fig. 10-c shows the performance of the averaged of amplitudes of fundamental currents $\left(\mathrm{I}_{\text {pavg. }}\right)$ while start up of induction motor. The results have shown that the supply current after compensation is almost in phase with the supply voltage, thus, an improvement in the power factor is achieved. 


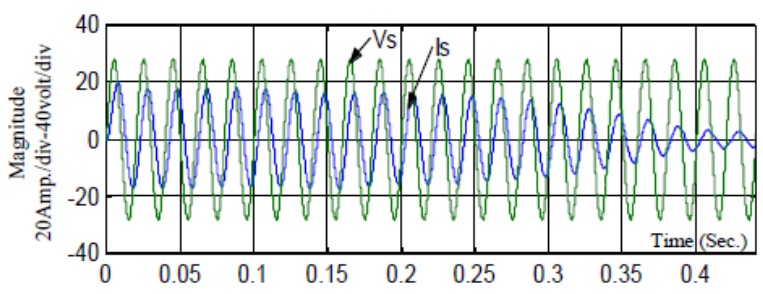

Fig.10-a The supply current $i_{s}$ with its respective voltage during run-up before compensation

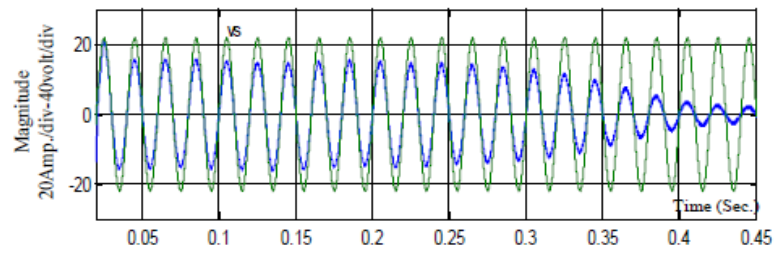

Fig.10-b The supply current $i_{s}$ with its respective voltage during run-up after compensation

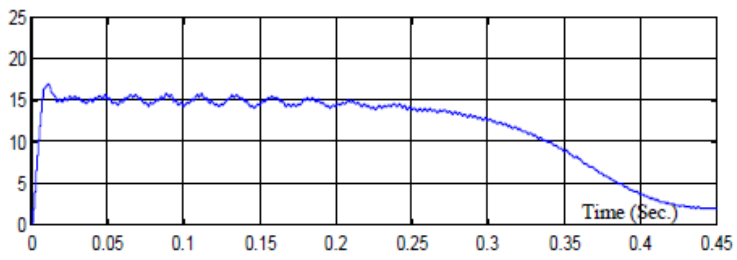

Fig.10-c Performance of the averaged of amplitudes of fundamental currents $\left(I_{\text {pavg. }}\right)$ while start up of induction motor.

\section{EXPERIMENTAL TESTS}

The three-phase shunt active power filter laboratory prototype has been implemented with the specified system parameters in Appendix. The proposed control algorithm is implemented using digital signal processor DSP (DS1104) manufactured by DSPACE company and developed under the integrated development environment of MATLAB-SIMULINK provided by the MATHWORK. The experimental circuit configuration is shown in Fig. 11.
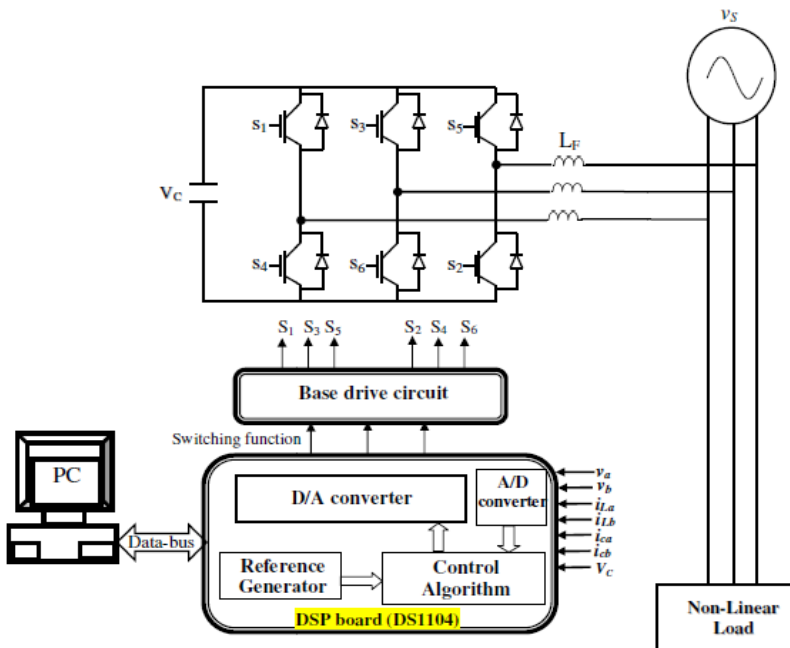

Fig.11 Experimental arrangement setup of shunt APF using DSP

A variety of waveforms show the experimental test results of the prototype for proposed method. Fig. 12 depicts the performances of source current before and after compensation when the firing angle of controlled rectifier $\alpha=0^{\circ}$

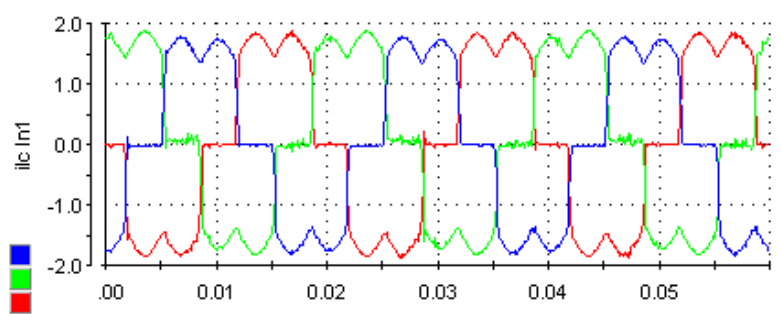

(a) 3-phase line current before compensation

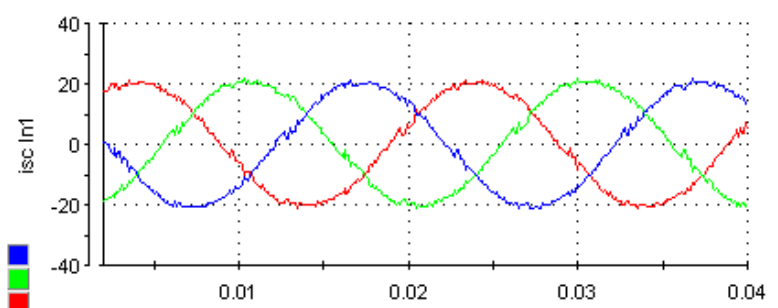

(b) 3-phase line current after compensation

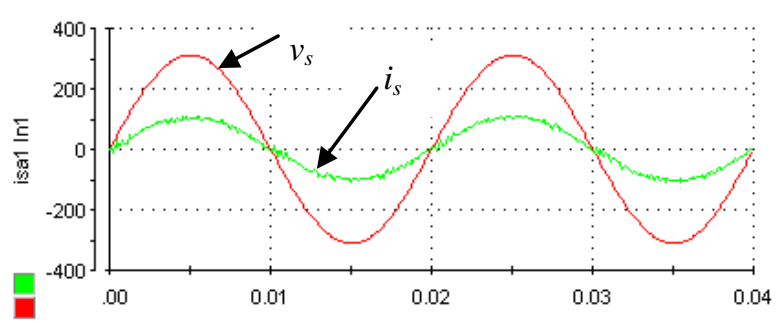

(c) Source current after compensation with its respective voltage

Fig.12 Performances of source current before and after compensation at firing angle $\alpha=0^{\circ}$

While Fig.13 shows the source current before and after compensation when the firing angle of controlled rectifier $\alpha=40^{\circ}$.

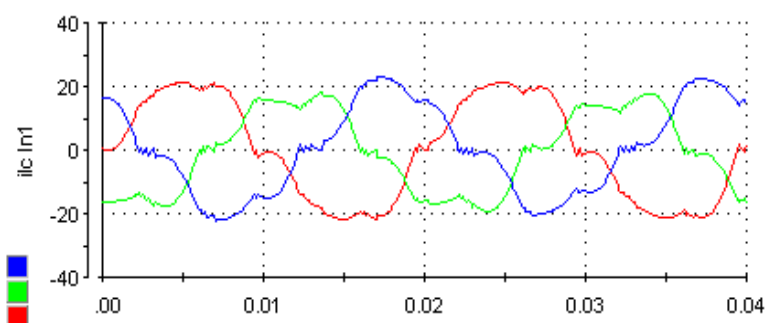

(a) 3-phase line current before compensation 


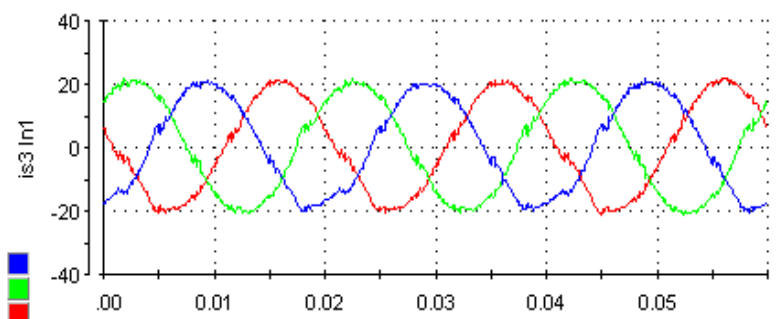

(b) 3-phase line current after compensation

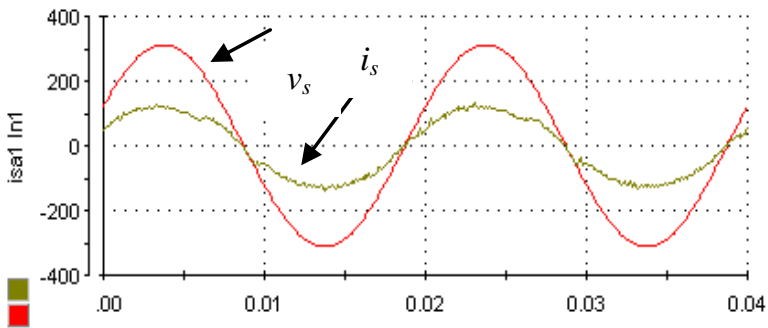

(c) Source current after compensation with its respective voltage

Fig.13 Performances of source current before and after compensation at firing angle $\alpha=40^{\circ}$

Through experimental results, it is revealed that the supply currents after compensating were found to be sinusoidal and in phase with its respective supply voltage, which was consistent with the simulation shown above. For this test, the outcome indicates that the proposed method is useful for the active filter studies and it indicates the effectiveness of the proposed controller for shunt APF under different conditions.

\section{CONCLUSION}

A new strategy to estimate harmonic distortion from nonlinear load current has been proposed. An Adaline neural network has been presented to determine precisely the necessary currents in order to cancel harmful harmonics. The proposed strategy was based on the Fourier series analysis of the current signals and LMS training algorithm carries out the weights. An experimental shunt APF has been carried out on DSP to explore the advantages and practical implementation with the proposed control strategy The simulations and experimental results have proven good performances and verify the feasibility of the proposed algorithm, and it is most effective under different conditions of nonlinearity of industrial applications.

\section{REFERENCES}

[1] Youssef K., "Industrial power quality problems Electricity Distribution," IEE Conf. Pub1 No. 482, vo1.2. June 2001, pp.18-21.

[2] Hugo.A, Ramos.C., Aurelio.M., and Gary W. C., 'Real-Time Shunt Active Power Filter Compensation', IEEE transaction on power delivery, Vol. 23, No. 4, October 2008

[3] H. Akagi, S. Srianthumrong, and Y. Tamai, "Comparisons in circuit configuration and filtering performance between hybrid and pure shunt active fitters", IEEE 38th Conf on Industry Applications, Vol. 2, October 2003, pp.1195-1202

[4] S.Rahmani, K. Al-Haddad,and F.Fnaiech. "A Three-Phase Shunt Active Power Filter for Damping of Harmonic Propagation in Power Distribution Systems " IEEE ISIE 2006, July 9-12, 2006, Montreal, Quebec, Canada, pp. 1760-1764.

[5] O. Abdelkhalek, C. Benachaiba, T. Benslimane, and M. Haidas, 'A Novel Theory of Reference Harmonic Current Identification Based on the PerUnit System Used for The Active Filters', Istanbul University - Journal of Electrical \& Electronics Engineering (IEEE), 2008 Vol. 8, No. 2, pp. 747-757.

[6] O. Abdelkhalek, C. Benachaiba, T. Benslimane, and M. Haidas, ' A Novel Theory of Reference Reactive Current Identification Based on the Per Unit System Used for The Active Filters ', Istanbul University - Journal of Electrical \& Electronics Engineering (IEEE), 2008 Vol. 8, No. 2, pp.759-767.

[7] N. K.Nguyen, D.Ould Abdeslam, P.Wira, D.Flieller, and J. Mercklé "Artificial Neural Networks for Harmonic Currents Identification in Active Power Filtering Schemes", IEEE conference, 2008,pp 2696-2701.

\section{Appendix A}

\section{The parameters of the Shunt APF}

Input voltages

Rectifier load resistance

Rectifier load current

SAF inductor

SAF DC link capacitor

SAF DC link voltage

Grid frequancy

$$
\begin{aligned}
\mathrm{v}_{\mathrm{s}} & =380 \text { volt } \\
\mathrm{R}_{\mathrm{dc}} & =25 \Omega \\
\mathrm{i}_{\mathrm{L}} & =20 \mathrm{Amp} . \\
\mathrm{L}_{\mathrm{f}} & =4 \mathrm{mH} \\
\mathrm{C} & =250 \mu \mathrm{F} \\
\mathrm{V}_{\mathrm{c}} & =750 \text { volt } \\
\mathrm{f}= & 50 \mathrm{~Hz}
\end{aligned}
$$

